\title{
Cruzando fronteras: espacio e identidad en el ensayo de Angelina Muñiz
}

\author{
Eugenia Helena HouvenAGHEL \\ Ghent University-Utrecht University \\ e.m.h.houvenaghel@uu.nl
}

\begin{abstract}
RESUMEN
En este estudio queremos aproximarnos a la identidad compleja de la escritora española exiliada en México Angelina Muñiz (1936). Para ello, analizamos la construcción del espacio en las recopilaciones de ensayos Las raices y las ramas (1993) y El canto del peregrino (1999). Metodológicamente, recurrimos al concepto de 'escenografía' propuesto por Dominique Maingueneau según el cual el texto pone en escena su propia situación de enunciación. Nuestro punto de partida es la triple identidad hispanojudeomexicana de la ensayista. Nos preguntamos qué posición ocupa la figura enunciadora frente a los espacios español y mexicano. Indagamos, además, en la presencia en los ensayos muñicianos del espacio correspondiente al aspecto judío de su identidad. Argumentamos que la concepción del espacio tal como se plasma en el ensayo de Muñiz no es topográfica, ni estática ni privilegia determinados territorios nacionales. Se trata, más bien de un espacio dinámico, abierto y libre que, igual que el espacio de la 'diáspora', se construye por encima de fronteras nacionales y distancias geográficas.
\end{abstract}

Palabras clave: ensayo, espacio, Generación Nepantla, exilio.

Crossing borders: Space and identity in the essay by Angelina Muñiz

\begin{abstract}
In this study, we establish a relation between the representation of space in Muñiz's essays and the construction of the essayist's complex identity which combines Spanish, Jewish and Mexican traits. We concentrate on Angelina Muñiz's essays Las raices y las ramas (1993) and El canto del peregrino (1999). Methodologically, we rely on Maingueneau's concept of 'scenography', according to which the text stages its own situation of enunciation. Our starting point is the triple Spanish-Jewish-Mexican identity of the essayist. Our research question is about how the essayist deals with the space corresponding to respectively the Spanish and Mexican part of her identity. Secondly, we analyse the representation in the essays of a space corresponding to her Jewish roots. We find that Muñiz's vision of space is not static; the essayist's vision on space is dynamic, open, free and characterized by a constant free movement across national borders. Similar to the concept of space of the 'diaspora', her vision is constructed without the limitations imposed by national borderlines or geographical distances.
\end{abstract}


Key words: essay, space, Nepantla Generation, exile.

SUMARIO: Introducción. 1. Las Raices y las ramas. 2. El canto del peregrino. 2.1. "Reflexiones sobre el exilio". 2.2. "El exilio español de 1939". 2.3. Hijos del exilio. 3. Conclusiones: "Las puertas del exilio".

\section{Introducción}

La identidad de la generación hispanomexicana ${ }^{1}$ a la que Angelina MuñizHuberman (1936) pertenece es polifacética. Hija de padres españoles que huyeron de España cuando estalló la Guerra Civil, Muñiz nació en Francia, en el camino hacia el exilio mexicano. Arribó en México y se naturalizó mexicana a los 6 años. A los 9 años, cuando la madre de Angelina Muñiz le comunicó que era judía, se agregó un tercer componente decisivo a la identidad cultural de la joven Angelina Muñiz. Su identidad se podría describir, a partir de aquel momento, como hispanojudeomexicana. Para aproximarnos a la mejor comprensión del proceso de la construcción identitaria de Muñiz optamos por estudiar la presencia espacial que adquieren las tres vertientes identitarias de Muñiz, en su ensayo.

En este trabajo, proponemos aproximarnos a la triple identidad de Angelina Muñiz-Huberman a través de la relectura de sus ensayos ${ }^{2}$, ya que la esencia del género ensayístico se halla en su condición subjetiva, en lo personal. El ensayo se construye, precisamente, en base al "yo"-ensayista. Los volúmenes seleccionados para análisis son Las raíces y las ramas (1993) y El canto del peregrino (1999), las dos primeras recopilaciones de ensayos de la mano de Muñiz, que giran en torno a dos temas muy vinculados a la compleja identidad muñiciana: el judaísmo y el exilio.

${ }^{1}$ La generación de adultos republicanos exiliados en México es conocida como "la primera generación del exilio". La segunda, a la que pertenece Tomás Segovia, es la de los hijos de esa primera generación, la llamada "generación hispanomexicanoa" o "generación de Nepantla" (término de Francisco de la Maza que refiere a una voz náhuatl que significa "en el medio, entre dos tierras") y es formada por los niños que siguieron el destino de sus padres y que llegaron en México entre sus dos y catorce años de edad. Entre los "hijos del exilio" se incluyen los autores siguientes: Manuel Durán (Barcelona, 1925), Roberto Ruiz (Madrid, 1925), Carlos Blanco Aguinaga (Guipúzcoa, 1926 - California 2013), Jomi García Ascot (Túnez, 1927 - México 1986), José de la Colina (Santander, 1934), Federico Patán (Gijón, 1937), Angelina Muñiz-Huberman (Hyères 1936), Nuria Parés (Barcelona 1925México 2010).

${ }^{2}$ A más de numerosos ensayos sueltos y ensayos publicados en volúmenes colectivos, Muñiz produjo dos recopilaciones ensayísticas en los años '90: Las raíces y las ramas (1993, FCE) y El canto del peregrino (1999, GEXEL). En el siglo XXI, Muñiz publicará tres recopilaciones ensayísticas más: El siglo del desencanto (2002), La sombra que cobija (2007) y Las vueltas a la noria (2013). 
Con el fin de aproximarnos a una mejor comprensión de los diferentes espacios vinculados a su identidad tal como se plasman en la ensayística de Muñiz, nos apoyamos metodológicamente en la 'escenografía'. Se trata de un concepto propuesto por Maingueneau para analizar la dinámica enunciativa del discurso que se compone de cuatro categorías interactivas e indisociables: enunciador, coenunciador, tiempo y espacio. Se trata concretamente de la manera en la que el propio ensayo "pone en escena" la figura del enunciador, la figura del coenunciador, el tiempo (cronografía) y el espacio (topografía) de la enunciación. De las cuatro categorías indisociables propuestas por Maingueneau nos va a interesar sobre todo la del espacio. Las preguntas que guían nuestra lectura son las siguientes: ¿Qué presencia adquieren España y México en la 'escenografía' de sus ensayos?, ¿Qué presencia adquiere el territorio judío?, ¿A qué escena cultural -la mexicana, la española, la judía- se concede mayor importancia?, ¿Qué tipo de relación se establece entre las diferentes zonas nacionales?, ¿Se recalcan las fronteras que separan los países entre ellos?, ¿Qué significado se da a las distancias geográficas?

Proponemos que la dimensión espacial adquiere presencia en los ensayos analizados no solo a través de la categoría espacial, sino también a través de las categorías del enunciador y del co-enunciador. El enunciador, al hablar de determinadas naciones, toma una determinada posición frente a ellas y se ubica, así, dentro o fuera de dichas zonas. Varios co-enunciadores de diferentes nacionalidades introducen, acorde con nuestra hipótesis, diversas facetas espaciales en los textos estudiados. ¿A qué tipo de lector se dirige el yo-enunciador?, ¿Con qué coenunciadores dialoga el yo-ensayista?, ¿Qué tipo de relación se establece entre los diferentes co-enunciadores y la figura del enunciador?, ¿Qué tipo de distancia separa los diversos co-enunciadores entre ellos y de la instancia enunciadora? Estas preguntas centradas en la categoría del enunciador y del co-enunciador guiarán nuestra lectura y nos ayudarán, de acuerdo a nuestra hipótesis, a sacar a luz la dimensión especial de los ensayos estudiados y aproximarnos, así, a la construcción discursiva de la identidad de Muñiz en los mismos.

\section{Las Raíces y las ramas}

El primer volumen ensayístico de Muñiz, titulado las Raices y las ramas $(1993)^{3}$, es el fruto de la investigación y de la reflexión de varios años (Muñiz 1993: 9) y su concepción se remonta, por lo tanto, a finales de los años 80 y principios de los 90. El volumen ofrece al lector un estudio del concepto de la Cábala y aborda así un tema que se convertirá en una de las constantes temáticas del ensayo de la

\footnotetext{
${ }^{3}$ En adelante abreviaremos: $R y R$.
} 
autora. ${ }^{4}$ En el prólogo (RyR: 9-10), lugar clave para la autodefinición de la figura enunciadora, el "yo-ensayista" explica que su libro nace de una preocupación intelectual profunda, relacionada estrechamente con la búsqueda de la vertiente judía de su identidad. La figura enunciadora se presenta como una investigadora ardua que recopila datos, acumula apuntes y lecturas de varios años. No se ubica a sí misma en un lugar geográfico concreto, sino que se sitúa en un espacio internacional de investigadores dialogantes, espacio que se representa en la amplia bibliografía (209-218). ${ }^{5}$ En las fuentes bibliográficas seleccionadas abundan referencias a libros de origen francés, español, italiano, inglés, estadounidense e israelí. La figura enunciadora se presenta no solo como una investigadora de orientación internacional, sino también modesta y consciente del carácter limitado de su estudio. ${ }^{6}$ En este contexto, subraya la posición privilegiada que España ocupa en la temática de Las raíces y las ramas: el mayor mérito de su trabajo se halla, a su modo de ver, en el aporte al estudio del impacto de la Cábala en la literatura medieval y renacentista española. ${ }^{7}$

${ }^{4}$ En efecto, aunque es en el marco mexicano que Muñiz produce su obra ensayística, llama la atención la escasa presencia de elementos temáticos mexicanos en la misma, mientras que el judaísmo y el exilio sí adquieren protagonismo. Esta ausencia del tema de México y de la literatura mexicana contrasta con la temática de los ensayos de otros miembros de la generación mexicana, tales como Tomás Segovia, Federico Patán, Pascual Buxó, que sí profundizan en la obra literaria de autores mexicanos y en la situación de México. Los tres volúmenes de ensayos disponen de índices analíticos, pero ninguno de los tres incluye el término 'México'.

${ }^{5}$ En el prólogo el la figura enunciadora declara que: "Me baso en el sistema de búsqueda de fuentes y derivaciones para centrarme únicamente en aquellas que considero más relevantes. Es, por lo tanto, un estudio selectivo y no exhaustivo. [...] Restrinjo la bibliografía, dada su inmensidad, a la que he utilizado exclusivamente para mi propósito." (RyR: 9)

${ }^{6}$ En palabras de Muñiz: "Mi aportación ha consistido en señalar apenas unas sendas en estos estudios, dentro de la literatura medieval y renacentista española. Más que nada he tratado de aclararme algunos conceptos como iniciación a un tema que exige constante estudio y que, dadas sus características, nunca termina de ser interpretada."

${ }^{7}$ El libro se estructura en dos partes que, en cuanto a la geografía temática, llevan el lector, en su mayor parte, a la zona de España y al sur de Francia. En la primera parte de este libro -las raíces- Muñiz estudia las fuentes del cabalismo hispanohebreo de los siglos XII y XIII en la región de Provenza y en España. En la segunda parte - las ramas- se ocupa de la cristianización de la Cábala y de las derivaciones posteriores de la Cábala en varios autores, principalmente autores españoles de la Edad Media y del Renacimiento. México es mencionado brevemente por la enunciadora cuando observa que la influencia posterior de la Cábala puede reconocerse en la poesía "del grupo de los Contemporáneos de México" (RyR: $126)$. Es de notar que la única mención a una derivación mexicana de la Cábala $(R y R: 126)$, la poesía de los Contemporáneos es, al mismo tiempo, la única influencia mexicana que 
Y veremos que, efectivamente, en los ensayos que siguen al prólogo, sólo se aludirá muy brevemente a las derivaciones de la Cábala fuera de España. ${ }^{8}$ México aparece, en este contexto, solo pocas veces. ${ }^{9}$ Una de estas ocasiones excepcionales se presenta cuando la autora conecta, sin profundizar, la Cábala con la poesía de los Contemporáneos en México. ${ }^{10}$ Es de notar que ni siquiera cuando se trata de fenómenos importantes para el judaísmo en México, la autora presta atención al tema. Es lo que ocurre, por ejemplo, cuando se menciona en el discurso al poeta novohispano Luis de Carbajal (RyR: 78). La figura enunciadora no explica su relevancia para la fundación de una tradición judía en la Nueva España: no aprovecha la oportunidad para aclarar que de Carbajal, 'el Mozo', fue gobernador de la colonia de Nuevo León, en el norte de México, en la que se estableció una gran comunidad criptojudía. Sin embargo, es precisamente con la herencia judía novohispana que el yo-ensayista pretende reanudar a través de sus ensayos y novelas inscritas en el neomisticismo (RyR: 9).

El volumen de ensayos se presenta a la vez como el resultado de varios años de investigación científica y como un instrumento para resolver inquietudes personales acerca del componente judío de su identidad. Así es que, en el umbral del texto, el lector sabe que tiene en sus manos una exploración intelectual y a la vez muy personal del concepto de la Cábala judía y sus frutos posteriores, escrita por una figura enunciadora que se presenta, en primer lugar, como una investigadora interesada en la Cábala judía y en sus manifestaciones en España.

Cuando dejamos el prólogo y pasamos a la lectura de los propios ensayos, llama la atención que la figura del lector adquiere muy poca presencia en esta primera recopilación de ensayos. En cambio, se incorpora en el ensayo la voz múltiple de teóricos, críticos y estudiosos contemporáneos con quienes la figura enunciadora dialoga y a partir de cuyas propuestas se aproxima al tema de su estudio. La mayor parte de los participantes en el discurso son estudiosos judíos de gran prestigio,

Muñiz menciona cuando describe la formación orientada hacia España y aislada de la realidad mexicana que caracteriza la generación hispanomexicana o de los "hijos del exilio" a la que pertenece (Muñiz, 1999: 158).

${ }^{8}$ Se trata de referencias a Israel o a la región del Mediterráneo.

${ }^{9}$ Alusiones a estudiosos o escritores mexicanos son las siguientes: la enunciadora se refiere (75) a un libro del autor hispanomexicano Luis Rius sobre la tradición medieval cristiana de las canciones de vela, publicado en México (1951); Muñiz cita del prólogo a este libro de la mano del estudioso mexicano Julio Torri (76), miembro del Ateneo de México; también se refiere brevemente a Sor Juana Inés de la Cruz (112).

${ }^{10}$ Es de notar que la única mención a una derivación mexicana de la Cábala $(R y R: 126)$, la poesía de los Contemporáneos, es, al mismo tiempo, la única influencia mexicana que Muñiz menciona cuando describe la formación orientada hacia España y aislada de la realidad mexicana que caracteriza la generación hispanomexicana o de los "hijos del exilio" a la que pertenece (Muñiz, 1999: 158). 
entre quienes destaca Ghershom Sholem, judío de origen alemán, considerado el fundador de los estudios modernos de la Cábala judía y el primer profesor del misticismo judío en la Universidad Hebrea de Jerusalén. ${ }^{11}$ La enunciación parece situarse, a partir del diálogo establecido con diversos especialistas judíos residentes en Israel, Europa o los EEUU, no tanto en un espacio geográfico limitado sino en un entorno más amplio, cosmopolita, en el que los vínculos intelectuales, la identidad judía y el interés por la Cábala transgreden fronteras nacionales.

En Las raices y las ramas, la representación de la enunciación en el texto subraya, más que nada, la ausencia de puntos de referencia mexicanos. Para empezar, no se aprovechan en el ensayo las posibilidades de conectar con el entorno mexicano. El lugar de la enunciación representado en el ensayo no corresponde al México geográfico, sino a un lugar de investigación que va por encima de fronteras nacionales. En segundo lugar, el lector está prácticamente ausente de la escena de enunciación. A través de la exclusión del lector de la situación enunciativa, se excluyen, obviamente, posibles referencias al lector mexicano y su circunstancia. España y el lector español adquiere mayor presencia ya que temáticamente se concede un rol importante al proceso de la recepción de la Cábala en la tierra española durante la Edad Media y el Renacimiento. En cambio, no se elaboran los fenómenos receptivos del cabalismo que, desde un punto de vista histórico o literario podrían dar más presencia a México en el volumen ensayístico, tales como el grupo de los Contemporáneos - conectado con la Cábala, según Muñiz- o el poeta novohispano Luis de Carvajal -importante para la fundación de una tradición judía en México-. Así es que se renuncia, en Las raíces y las ramas, a más de una posibilidad para conectar con la sociedad mexicana, su historia, su realidad geográfica, su cultura y su público lector. Si bien es cierto que el volumen se publica en México, no se plasma en el texto la idea de haberse escrito para los mexicanos, ni mucho menos.

Se aprovecha, al contrario, otra estrategia escenográfica para conectar con otro colectivo diferente, ni español ni mexicano. En el ensayo se crea una alianza muy fuerte entre la figura enunciadora y un co-enunciador múltiple, compuesto, principalmente, de especialistas judíos oriundos de diferentes países y residentes en diferentes países. Así es que la construcción de la escena de enunciación del volumen, en base a la figura del co-enunciador, recalca, esencialmente, el 'sentirse

${ }^{11}$ Otro participante en el discurso es el alumno de Gershom Sholem, Moshé Idel, judío de origen rumaní, profesor de pensamiento judío en la Universidad Hebrea de Jerusalén y miembro de la Academia israelí. También Susan Handelman, judío de origen estadounidense, profesora a la Universidad Bar-Ilán de Ramat-Gan (Israel) y escritora de libros sobre el pensamiento judío es una de las voces prestigiosas que participa en el discurso de Las raices y las ramas. Hay numerosos otros ejemplos de participantes de origen judío que residen en diferentes países: Yosef Hayim Yerushalmi, Maurice-Ruben Hayoun, Emile Touati, Seymour B. Liebman entre otros. 
diferente' de la figura enunciadora en la sociedad mexicana y el pertenecer a la comunidad judía antes que a la mexicana. Este intercambio de ideas y conocimientos acerca de la Cábala, creado por encima de las fronteras geográficas, no solo completa y enriquece el discurso monológico del yo-ensayista sino que también tiene un efecto en la imagen que tenemos de la propia figura enunciadora. Gracias al establecimiento de dicho diálogo con la voz del especialista judío, la figura enunciadora se vincula estrechamente con una amplia red de estudiosos judíos de gran prestigio.

Concluimos del análisis de la categoría espacial de la 'escenografía' de Las raíces y las ramas que aunque en los ensayos escasean marcadores espaciales explícitos que sitúan la enunciación en un determinado lugar, los textos no carecen de dimensión espacial. En Las raíces y las ramas, la dimensión espacial adquiere presencia a través de la categoría del co-enunciador, que es judío y del enunciador, que se autodefine en relación con la herencia judía. Las dimensiones y estructuras de la dimensión espacial tal como se construye en Las raices y las ramas se parece, así, al territorio amplio de la diáspora judía, que trasciende las fronteras nacionales.

\section{El canto del peregrino}

El exilio y la literatura del exilio son dos núcleos temáticos omnipresentes en la obra ensayística de Angelina Muñiz. En la segunda recopilación de ensayos de la mano de Muñiz, El canto del peregrino, que reúne conferencias pronunciadas en $1995^{12}$, se concede un papel principal al exilio. Se abordan varios aspectos del exilio: el exilio como concepto, el exilio de escritores de diferentes países a través de la historia, el exilio como tema en la literatura, el exilio como clave para entender el siglo XX. ${ }^{13}$ La recopilación salió en 1999 y es una coedición de GEXEL (Grupo de Estudios del Exilio Literario) en Barcelona y la Universidad Nacional Autónoma en México, y su situación editorial refleja, así, la ubicación entre España

12 Los ensayos reunidos en esta recopilación fueron expuestos en la Cátedra Extraordinaria Maestros del Exilio Español de la UNAM en 1995. La etapa final de investigación y de redacción del libro se hizo en 1997.

${ }^{13}$ Es bien sabido que la autora usa la imagen del exilio para ubicarse: privilegiando los conceptos de la lengua y la literatura, sitúa su patria en "el cultivo de la lengua"; para situar su casa en el exilio, que se presenta como un lugar geográfico muy preciso, como un hogar. "Cuando comprendí que el exilio era mi casa, abrí la puerta y me instalé, me instalé cómodamente. Con [...] mis libros favoritos, mi peculiar manera de escribir, mi gata prodigiosa, muchas hojas de papel, plantas en el balcón, un comedero para los colibríes y otro para los petirrojos [...]" (CP: 186) describe su tierra como "la tierra de las palabras", dice que "halla nacionalidad en el quehacer de la literatura" (CP 160). Muñiz sitúa, de esta manera, su patria y su casa en los lugares metafóricos de la lengua y de la literatura. El hecho de que Muñiz recurre a la imagen del exilio como un lugar, en vez de referirse a su país adoptivo, México, es significativo para aproximarnos a la construcción de su identidad. 
y México de los republicanos exiliados. También la realización del volumen ensayístico se hace entre México y España: se trata de ensayos expuestos por primera vez en la UNAM (en la Cátedra Extraordinaria Maestros del Exilio Español, en 1995) y finalizados gracias a una beca del Ministerio de Asuntos Exteriores de España, en 1997.

\section{"Reflexiones sobre el exilio"}

Al iniciar el primer ensayo del volumen "Reflexiones sobre el exilio" (Muñiz 1999: 65-86), la figura enunciadora define enseguida el tema del exilio, centro de este volumen, como una constante en "nuestro siglo" y sitúa así el momento de la enunciación a finales del siglo XX. Abundan las referencias a elementos de la historia del siglo XX; en base a ellas, se aproximan la figura enunciadora y el coenunciador y forman un colectivo; en base a ellas, el acto de la enunciación está anclado en el tiempo, más que en el espacio. Bajo la perspectiva de fines de siglo, se exploran, en el segundo capítulo del ensayo ("Exilio y modernidad" Muñiz 1999: 87-114), la historia y la experiencia del exilio para aproximarse a una poética del exilio. A través del comentario de vivencias exílicas muy diferentes entre ellas y muy diversas desde el punto de vista espacial — como los de Edmond Jabès, judeoegipcio exiliado en París, de Joseph Brodsky, judío oriundo de la Unión Soviética y exiliado en los Estados Unidos, de James Joyce, irlandés exiliado entre otros en Trieste, París y Zürich, de José Kozer, judeocubano exiliado en Nueva York, de Emil M Cioran oriundo de Rumania y exiliado en París, de Witold Gombrowicz de origen polaco y exiliado en Argentina-, la figura enunciadora se aproxima desde un enfoque espacial amplio a la esencia del exilio. Ni la figura enunciadora, ni el acto de la enunciación, ni la figura del receptor se sitúan en México o en España. El entorno en el que se sitúa esta escena de la enunciación no corresponde, pues, a un lugar geográfico concreto sino que se caracteriza como un lugar de encuentro intelectual, cosmopolita en el que se juntan y se comentan las vivencias de exiliados en diferentes partes del mundo.

\section{"El exilio español de 1939"}

Se reduce, en el apartado siguiente (115-154), la amplitud del contexto internacional del exilio al caso exílico concreto causado por la Guerra Civil española. Entre los casos del exilio republicano, la ensayista selecciona dos vivencias exílicas de escritores españoles en México: la de la figura emblemática María Zambrano y la de Enrique Díez-Canedo. Aunque una breve o más larga estancia en México es lo que los dos casos estudiados tienen en común, la visión de la enunciadora es claramente española. Titula el apartado "el exilio español de 1939" y considera a Zambrano, Díez-Canedo y la generación hispanomexicana como "algunos autores, algunos momentos derivados de esa gran rama de la historia española que siguió viviendo en México" (Muñiz 1999: 115). México se considera 
como el espacio en el que la cultura y literatura de España, en época de crisis en la propia tierra española, encuentran un punto de ramificación.

El primer caso abordado es el de María Zambrano (Muñiz 115-138) ${ }^{14}$, quien pasó por México en los años 1939-1940, antes de su salida rumbo a Cuba en el mismo año 1940. Se trata solo de un episodio breve, no obstante, Muñiz opta por enfocar, en su ensayo, dicha primera experiencia exílica de Zambrano en México. Sin embargo, la figura enunciadora no adopta en su discurso un punto de vista mexicano sino que su aproximación a la tierra mexicana se hace bajo una perspectiva española. En efecto, México no equivale a una realidad geográfica, social, política y cultural con sus propias características, sino a un espacio de refugio, a la tierra del exilio. Dicho espacio se describe por oposición a España y a través de los ojos del español que se encuentra en el exilio mexicano después de la Guerra Civil. México se presenta únicamente en términos que corresponden a la experiencia del exiliado republicano: como lugar del "dolor exílico" (Muñiz, 1993: $116,121)$, como tierra que "remueve la mente en busca de explicaciones, de respuestas a porqués, de reflexiones con el tinte de la emoción, de lamentos" (Muñiz, 1993: 116), como lugar alejado de España (Muñiz, 1993: 121), como tierra de la "soledad", de la "tristeza" y de la "melancolía" (Muñiz, 1993: 121). En suma, "en tierra mexicana y con el dolor constante del exilio y de la lejanía de España", se encuentra María Zambrano, figura que para Muñiz representa, como una figura simbólica, el exilio republicano. Este contexto del primer exilio en que, como escribió Alfonso Reyes ${ }^{15}$, "el mundo entero lloraba por ella" (Muñiz 1993: 121) le "propició" [a Zambrano] la situación de ajuste de cuentas que conlleva todo exilio"

${ }^{14}$ El ensayo apareció por primera vez en La Jornada Semanal en 1991. Posteriormente, el mismo ensayo "María Zambrano: castillo de razones y sueño de la inocencia" se incluye en dos recopilaciones de ensayos: El Canto del peregrino (115-131) y El siglo del desencanto (109-126).

${ }^{15}$ En el discurso de Muñiz, aparecen palabras consoladoras de Alfonso Reyes, uno de los mexicanos que se ocupó de María Zambrano a través de una intensa correspondencia, estudiada por Stanton durante este período difícil para la filósofa española. Sin embargo, llama la atención la ausencia de referencias a la manera en la que fue enviada de México D.F. a Morelia, una ciudad en Michoacán. Octavio Paz, amigo de María Zambrano, resume el episodio como sigue: "Daniel Cosío Villegas [...] la [María Zambrano] había contratado para que formase parte de la Casa de España (después transformada en Colegio de México) y diese cursos de filosofía. Pero hubo, según parece, cierta oposición entre algunos de sus colegas (¡una mujer profesora de filosofía!) y se decidió enviarla a Morelia. Sin apenas darle tiempo a descansar y conocer un poco de la ciudad, con aquella indiferencia frente a la sensibilidad ajena que era uno de los rasgos menos simpáticos de su carácter, Cosío Villegas la despachó inmediatamente a Morelia. La ciudad es encantadora pero María se sintió perdida, lejos de sus amigos y en un mundo ajeno a sus preocupaciones. Cada vez que podía, visitaba México." (Paz, 199: 22-23) 
(Muñiz 1993: 126) y le ofreció, después, este punto de ramificación, la oportunidad de continuar su obra filosófica iniciada ya en España.

En el ensayo dedicado a Enrique Díez Canedo, quien se estableció en México en 1938 hasta su muerte en 1944, la figura enunciadora tampoco adopta un enfoque mexicano, sino que le considera al autor, crítico y traductor-a quien denomina de manera significativa, usando las palabras de Alfonso Reyes, "el americano de España"- en el contexto del diálogo entre Europa y América. En efecto, la figura enunciadora desarrolla, sobre todo, la dinámica transatlántica de la obra de Díez Canedo. Subraya, para empezar, su importancia para la difusión de la cultura europea dentro de España e Iberoamérica. Recalca, también, la importancia de sus estancias en diferentes países iberoamericanos y de sus contactos en España con autores hispanoamericanos. Destaca, asimismo, el término "influencia de retorno" (Muñiz 1999: 145) con el cual Díez Canedo se refiere a la influencia de la cultura americana en Europa. En resumen, el discurso de Angelina Muñiz se sitúa en un ámbito transatlántico, en el que predomina la idea de una transgresión de fronteras y de una fertilización cruzada entre culturas más allá de las fronteras nacionales y más allá de distancias geográficas.

\section{"Hijos del exilio"}

En las secciones siguientes del volumen, se enfoca la situación de los hijos del exilio republicano en México, la llamada generación hispanomexicana -a la que pertenece la propia Angelina Muñiz- y se comenta su obra literaria bajo el enfoque del exilio (Muñiz 1999: 155 y ss.). Para caracterizar la generación "formada por hijos de exiliados que llegaron a México a raíz de la guerra civil española", la figura enunciadora recurre, primero, a imágenes de movimiento espacial. Describe, concretamente, la ruta que siguieron los hijos del exilio antes de llegar a México: "La vía de salida es la misma: de España a Francia, a América (con estancias temporales en Santo Domino o en Cuba) y, finalmente, en México." (Muñiz 1999: 157) Las características espaciales de la generación de los hijos del exilio se relacionan, precisamente, con su aptitud para traspasar fronteras nacionales y cambiar países: "la capacidad de adaptación", "la inquietud viajera", "la observación de costumbres" y "el aprendizaje de otras lenguas" son los factores que definen su horizonte espacial (Muñiz 1999: 157). La actitud cosmopolita y la mentalidad universal son los primeros rasgos definitorios de la generación hispanomexicana.

La toma de distancia frente a México es, para la figura enunciadora, el segundo rasgo espacial caracterizador de los 'hijos del exilio'. Se destaca el carácter aislado de la educación de los jóvenes españoles recién llegados a México: "Esos niños fueron educados como si el retorno a España hubiera de ser inminente y como si vivieran en una realidad ajena a la mexicana." (Muñiz 1999: 156). "Su educación 
pertenece más al ámbito europeo que al mexicano, lo que los aísla del medio mexicano" (Muñiz 1999: 158) ${ }^{16}$. Aislamiento, alejamiento y marginalización son las pautas que determinan la ubicación de la joven generación hispanomexicana más bien fuera que dentro de México. La enunciadora reduce la importancia de la ubicación geográfica concreta que les toca a los jóvenes hijos del exilio al contrastarla con la relevancia de otros componentes, más allá de las fronteras geográficas y nacionales para su construcción identitaria.

Posteriormente, los "hijos del exilio", ya convertidos en escritores adultos, "no se incorporaban a la comunidad de escritores mexicanos" (Muñiz 1999: 159). La generación hispanomexicana "no encontró", según la figura enunciadora, "su acomodo dentro de la sociedad mexicana" (Muñiz 1999: 155). La dificultosa integración de los hijos del exilio se expresa en términos espaciales: "a su alrededor", destaca la enunciadora, "se sentía el vacío" (Muñiz 1999: 159); "una especie de capullo los protegía y los apartaba" (Muñiz 1999: 159).

Si la generación se caracteriza por su actitud cosmopolita y su capacidad de adaptación, ¿a qué se debe esta integración defectuosa en la sociedad y cultura mexicanas? La causa se halla, acorde al discurso de Muñiz, en la tendencia al "nacionalismo" de la sociedad mexicana (Muñiz 1999: 155) y a la moda literaria "nacionalista" (Muñiz 1999: 188) vigente en México en los años 60 cuando la generación hispanomexicana empezó a publicar. El propio cosmopolitismo es lo que aparta a la generación hispanomexicana del mundo "nacionalista" de la literatura en México. ${ }^{17}$ La figura enunciadora se refiere a las épocas "de acentuado nacionalismo" en las que la generación hispanoamexicana fue "si no rechazada, por lo menos, marginada" (Muñiz 1999: 155). También se refiere al tipo de escritura que el autor exiliado, que se encuentra "en un medio diferente (si no hostil) que no lo acoge", debe desarrollar necesariamente: "sólo en el caso de que descubra nuevas vías de expresión (que, claro, nunca serán de índole nacionalista), podrá sobrevivir" (Muñiz 1999: 164). La figura enunciadora retoma la misma idea en el contexto de su propia escritura individual: "Escogí", dice la enunciadora, "(sin darme cuenta en

\footnotetext{
${ }^{16}$ La única influencia mexicana en esta generación que Muñiz menciona es la del grupo de los Contemporáneos (CP 158).

${ }^{17}$ Muñiz profundiza en este contraste entre el cosmopolitismo de los escritores exiliados republicanos en México y el nacionalismo de los escritores mexicanos en una entrevista recuperada en Puente@Europa: "En cuanto a los exiliados, su posición se inclinaba a identificarse con los hechos que sucedían en Europa, especialmente durante la Segunda Guerra, con lo cual también se alejaban de los problemas locales del país en el que habitaban. Por ejemplo, un poeta español exiliado, León Felipe, estaba más inclinado a escribir un poema sobre la muerte de un niño judío en Auschwitz que sobre la pobreza en México. Mientras que un poeta mexicano, por ejemplo, López Velarde, se preocupaba por la realidad mexicana y su cercanía con los Estados Unidos. Así, el poeta exiliado alcanza el universalismo y rechaza el nacionalismo."
} 
ese momento), temas y personajes alejados de la realidad literaria mexicana que me permitieran ahondar en mundos sin fronteras y en situaciones universales." (Muñiz, 1999: 187-188).

La generación hispanomexicana, acorde con su mentalidad cosmopolita, busca en la actividad literaria una vía de salida del entorno nacional. "Por fin", concluye la enunciadora, los hijos del exilio, "hallan nacionalidad en el quehacer de la escritura" que es, ante todo, "libre". (Muñiz 1999: 160) Las imágenes que la figura enunciadora utiliza para describir el mundo literario que se construye para sí misma, abunda en aperturas para salir: "túneles", "pasadizos", "ventanales", "escalas", "puertas" (Muñiz 1999: 187). En oposición con esta serie de imágenes, la figura enunciadora aproxima la idea de una nacionalidad mexicana a una casa cerrada: los hijos del exilio, explica la figura enunciadora no buscan "casas, sino puertas" (Muñiz 1999: 188). Así es que la figura enunciadora describe la obra literaria de los hijos del exilio como una apertura hacia otro espacio diferente: un espacio sin fronteras, un universo abierto, un mundo sin límites.

\section{Conclusiones: "La puerta del exilio"}

El espacio adquiere, en ambas recopilaciones ensayísticas de Angelina Muñiz, un sentido más simbólico que geográfico. Los lugares abordados, tales como México o España, no se describen en términos realistas. Se construyen, más bien, en términos abstractos, como símbolos, bien de lo perdido y de la esperanza, bien de la lejanía y del dolor. Se trata, asimismo, de un espacio que carece de fronteras. En Las raíces y las ramas, la figura enunciadora cruza libremente fronteras para dialogar con un gran número de co-enunciadores de muy variadas nacionalidades. En El canto del peregrino, considera el exilio bajo un enfoque universalista al vincular, por encima de las distancias geográficas que las separan, vivencias exílicas muy diversas.

El espacio se construye, en segundo lugar, como un universo dinámico en el que los movimientos y las transgresiones predominan. Aunque dichos movimientos migratorios dan lugar, en un nivel realista, a pérdidas y a la creación de distancias dolorosas, en un sentido figurado, dichos movimientos se presentan como creativos y enriquecedores. Las entidades espaciales demasiado encerradas en sí mismas y que no permiten movimientos son presentadas como espacios sofocantes.

La concepción simbólica y dinámica del espacio tal como se plasma en la ensayística de Muñiz ofrece la oportunidad de repensar y representar la literatura y la investigación en términos espaciales. En ambos casos, se trata de zonas sin fronteras. El espacio de la investigación corresponde a un lugar de encuentro intelectual. Se trata de un territorio libre de fronteras, en el que los contactos e intercambios predominan sobre las posiciones que cada uno toma y sobre las distancias geográficas. El espacio de la literatura no se presenta tanto como un espacio sino como una apertura hacia la libertad, una vía de salida hacia una zona libre de limitaciones. 
Así es que la construcción del espacio muñiciano guarda semejanza con la noción de 'diáspora', en cuyo corazón se encuentra la idea del cruce de líneas fronterizas: "El concepto de diáspora señala procesos de múltiples direcciones a través de fronteras geográficas, culturales y psíquicas." (Marcu 2012: 164) En efecto, la palabra diáspora significa originalmente, en griego, 'dispersión' o 'diseminación'. Angelina Muñiz problematiza y cuestiona, en su ensayo, la confluencia de la frontera nacional con la cultura nacional y propone un espacio regido por el movimiento transgresor de la diáspora.

Este análisis del espacio en el ensayo de Angelina Muñiz nos permite plantear la construcción identitaria de la autora en términos espaciales. No se trata tanto de una triple identidad en la que se yuxtaponen diferentes componentes nacionales, culturales o religiosos de manera estática. La esencia de su identidad se halla en el movimiento mismo entre diferentes zonas, en la puerta siempre abierta que permite el movimiento liberador y transgresor de una cultura a otra.

\section{BIBLIOGRAFÍA}

[S. A.]

2007 "An interview with Angelina Muñiz-Huberman/Entrevista a Angelina Muñiz-Huberman", Puente @ Europa - Año V - Número 3/4 - Noviembre 2007. Disponible en línea en:

http://www.ba.unibo.it/NR/rdonlyres/DA1908CA-D3F4-46EA97F1-0B4761D343FC/102057/PuenteEuropaN34A5Muiz_es.pdf

BERNÁRNDEZ, Mariana.

1993 "En el centro el exilio. Entrevista con Angelina Muñiz", La jornada Semanal. Suplemento cultural (12.09.1993)

MARCU MARCU, Silvia.

2012 De Rusia a España: Movimientos Migratorios Transfronterizos. Madrid: UNED.

MENTON, Seymour.

1993 La nueva novela histórica de la América Latina (1979-1992).

México: Fondo de Cultura Económica.

MUÑIZ, Angelina.

1993 Las raices y las ramas. México: FCE.

1999 El canto del peregrino. Barcelona/México: GEXEL

2002 El siglo del desencanto. México: FCE.

2007 La sombra que cobija. México: UNAM.

2013 Las vueltas a la Noria. México: UNAM. 